\title{
Gangguan pola tidur-bangun setelah cedera kepala
}

\author{
Moses Kharisma Setyawan ${ }^{1 *}$, Sri Maliawan², Tjokorda Gde Bagus Mahadewa², \\ I Wayan Niryana², Dewa Putu Wisnu Wardhana²
}

Published by Intisari Sains Medis

PProgram Studi Sarjana Kedokteran dan Profesi Dokter, Fakultas Kedokteran, Universitas Udayana; ${ }^{2}$ Divisi/KSM Bedah Saraf, Fakultas Kedokteran Universitas Udayana/RSUP Sanglah Denpasar.

\section{*Korespondensi:}

Moses Kharisma Setyawan;

Program Studi Sarjana Kedokteran dan Profesi Dokter, Fakultas Kedokteran, Universitas Udayana; mosesk.sno.28@gmail.com

Diterima: $26-03-2021$

Disetujui: 02-07-2021

Diterbitkan: 12-07-2021

\section{ABSTRACT}

Traumatic brain injury is a common trauma. Traumatic brain injury is commonly followed by sleep disorder such as insomnia, hypersomnia and circadian rhythm disturbance. Sleep disorder can cause many complications, including the worsening of the brain injury prognosis. Insomnia occurs in $29 \%$ traumatic brain injury patient. Insomnia suspected due injury in inferior frontal, anterior temporal including basal forebrain, also sympathetic nerve hyperactivity. Insomnia increase the risk of stroke, disability and mood disturbance. Hypersomnia occurs in $28 \%$ traumatic brain injury patients. Hypersomnia suspected due orexin decrease and injury in sleep promoting area. Hypersomnia suspected related to recovery, less activity time and accident due sleepiness. There are no

prevalence data of circadian rhythm disturbance after traumatic brain injury. This disturbance is caused by injury in supra-chiasmatic nucleus and related to global worsening on the patient. Insomnia and circadian rhythm disturbance are highly linked with injury area, but hypersomnia is not particularly linked to any area and only related to orexin decrease. Insomnia and circadian rhythm disturbance are highly related to the worsening condition on the patient, but hypersomnia is associated with recovery and not particularly related to any disturbances. It is hoped that understanding the sleep disorder after traumatic brain injury can rise the alertness of this matter and encourage clinicians to increase the quality of sleep disorder due to traumatic brain injury management.

Keywords: Circadian rhythm disturbance, hypersomnia, insomnia, sleep disturbance, traumatic brain injury. Cite This Article: Setyawan, M.K., Maliawan, S., Mahadewa, T.G.B., Niryana, I.W., Wardhana, D.P.W. 2021. Gangguan pola tidur-bangun setelah cedera kepala. Intisari Sains Medis 12(2): 444-448. D0l: 10.15562/ism. v12i2.1013

\section{ABSTRAK}

Cedera kepala merupakan salah satu cedera yang umum terjadi. Cedera ini sering diikuti dengan gangguan tidur seperti insomnia, hipersomnia dan gangguan ritme sirkadian. Gangguan ini sering dapat menyebabkan berbagai komplikasi termasuk memperparah penyembuhan cedera kepala. Insomnia setelah cedera kepala terjadi sebanyak $29 \%$. Insomnia diduga disebabkan oleh cedera pada daerah inferior frontal, anterior temporal termasuk basal otak depan, juga peningkatan kerja saraf simpatis. Insomnia meningkatkan resiko stroke, disabilitas dan gangguan suasana hati. Hipersomnia setelah cedera kepala terjadi sebanyak 28\%. Hipersomnia diduga akibat penurunan orexin dan akibat kerusakan pada area yang mempertahankan bangun. Hipersomnia diduga berhubungan dengan penyembuhan, waktu tersita akibat tidur dan kecelakaan akibat mengantuk. Belum

ada data prevalensi gangguan ritme sirkadian setelah cedera kepala. Gangguan ini disebabkan oleh cedera pada nukleus suprakiasmatik dan sering dikaitkan dengan perburukan kondisi pasien. Insomnia dan gangguan ritme sirkadian sering dihubungkan dengan lokasi tertentu dari cedera, namun hipersomnia berhubungan dengan kadar orexin dan tidak terlalu dikaitkan terhadap area tertentu. Insomnia dan gangguan ritme sirkadian berhubungan dengan perburukan, namun hipersomnia bisa menandakan perbaikan dan tidak berhubungan signifikan dengan gangguan lainnya. Diharapkan dengan memahami gangguan tidur ini dapat meningkatkan kewaspadaan bagi para klinisi dan mendorong untuk penelitian berikutnya sehingga penanganan pasien gangguan tidur akibat cedera kepala dapat menjadi lebih baik.

Kata kunci: Cedera kepala, gangguan ritme sirkadian gangguan tidur, hipersomnia, insomnia.

Sitasi Artikel ini: Setyawan, M.K., Maliawan, S., Mahadewa, T.G.B., Niryana, I.W., Wardhana, D.P.W. 2021. Gangguan pola tidur-bangun setelah cedera kepala. Intisari Sains Medis 12(2): 444-448. D0I: 10.15562/ism. v12i2.1013 


\section{PENDAHULUAN}

Cedera kepala merupakan gangguan pada otak yang terjadi karena benturan fisik dari luar. Insiden cedera kepala di dunia mencapai 939 kasus setiap 100.000 populasi dan diperkirakan 69 juta orang mengalami cedera kepala setiap tahunnya. ${ }^{1}$ Pada hasil RISKESDAS 2018 prevalensi dari cedera kepala di Indonesia mencapai $0,2 \%$ dari populasi, sama halnya dengan prevalensi cedera kepala di Bali yang mencapai $0,2 \%$ dari seluruh populasi. ${ }^{2}$

Salah satu komplikasi umum dari cedera kepala adalah gangguan pola tidur, dimana sebesar $30-70 \%$ dari populasi dengan cedera kepala mengalami hal ini. ${ }^{3-5}$ Gangguan pola tidur ini bisa bertahan, atau bahkan menjadi progresif dalam jangka waktu 1-3 tahun. ${ }^{6,7}$ Gangguan tidur yang biasa terjadi pada pasien dengan cedera kepala adalah insomnia, hipersomnia, dan gangguan ritme sirkadian (circardian rhythm disturbance). ${ }^{8,9}$ Kesadaran masyarakat untuk melaporkan gangguan tidur juga dinilai sangat kurang sehingga penanganan yang diberikan terlambat atau bahkan tidak diberikan penanganan yang sesuai. Oleh sebab itu, gangguan pola tidur-bangun dapat menjadi lebih parah dan berlanjut hingga jangka panjang.

Gangguan tidur setelah cedera kepala jika tidak ditangani dengan baik akan dapat menyebabkan berbagai komplikasi, termasuk memperlambat penyembuhan cedera kepala itu sendiri. Sebuah penelitian menyatakan bahwa pasien yang mengalami gangguan ritme sirkadian lebih dari delapan hari akan menjalani perawatan yang lebih lama, amnesia yang lebih parah dan disabilitas yang lebih banyak. ${ }^{10}$ Munculnya insomnia dihubungkan dengan perburukan prognosis termasuk meningkatnya kemungkinan stroke. ${ }^{11}$ Selain itu, insomnia yang disertai rasa sakit dihubungkan dengan meningkatnya disabilitas. ${ }^{12}$

Salah satu kunci penting dari penanganan cedera kepala adalah penanganan gangguan tidur yang baik. Penanganan gangguan tidur yang baik dapat meningkatkan kualitas hidup pasien, namun sampai sekarang masih ada banyak informasi mengenai gangguan pola tidur-bangun setelah cedera cedera kepala yang belum diketahui. Informasi tentang mekanisme terjadinya gangguan pola tidur-bangun setelah cedera kepala dan dampaknya akan menjadi dasar teori dalam penanganan pasien. Dengan memahami hal ini diharapkan akan meningkatkan kewaspadaan terhadap gangguan pola tidur-bangun setelah cedera kepala dan akan memberikan dorongan untuk penelitian selanjutnya sehingga penanganan pasien cedera kepala dapat terlaksana dengan lebih baik.

\section{METODE}

Penulisan dilakukan secara deskriptif menggunakan metode narrative review menggunakan berbagai sumber jurnal. Jurnal diambil secara daring dari Pubmed dengan batasan 10 tahun terakhir yang ditulis dalam bahasa Inggris (English) dengan desain uji klinis, kohort, kasuskontrol dan potong-lintang. Jika terdapat penelitian dengan topik penting dan belum ada penelitian terbaru, maka digunakan jurnal yang lebih tua. Pencarian jurnal menggunakan kata kunci awal "Circadian rhythm disturbance AND Traumatic Brain Injury" dan "Circadian rhythm disturbance AND TBI”. Jurnaljurnal terkait ditelusuri secara manual dengan mengkaji abstrak naskah yang terkait jurnal dari pencarian awal. Dari 83 jurnal yang didapat, dipilih 74 jurnal untuk dilakukan sintesis secara naratif, tujuh jurnal tidak dipilih karena tidak tersedia secara lengkap dan dua jurnal tidak terpilih karena tersedia hanya dalam bahasa yang tidak dipahami penulis. Dari 74 jurnal didapat 23 jurnal mengandung penelitian penting yang menjadi dasar penarikan hasil.

\section{HASIL}

\section{Insomnia Setelah Cedera Kepala}

Insomnia setelah cedera kepala memiliki prevalensi yang beragam. Data prevalensi insomnia yang didapatkan dari telaah literatur adalah berkisar antara $10 \%$ hingga $38 \% .^{3,6,13-15}$ Didapatkan bahwa prevalensi insomnia akan meningkat saat terjadi cedera kepala kedua. ${ }^{14}$ Ada penelitian yang menyatakan bahwa insomnia paling sering dijumpai pada cedera kepala ringan (CKR), namun terdapat penelitian lain yang mengatakan bahwa insomnia paling sering dijumpai pada cedera kepala sedang (CKS). ${ }^{7,15}$
Insomnia setelah cedera kepala dapat muncul dalam rentang waktu yang beragam. Insomnia dapat muncul dalam hitungan hari bahkan bisa menetap sampai tiga tahun.,16 Insomnia juga dikaitkan dengan peningkatan kerja saraf simpatis yang ditandai dengan peningkatan detak jantung pada pasien insomnia. Mekanisme yang sama juga dicurigai sebagai penyebab peningkatan kepekaan terhadap stimulus cahaya dan suara pada pasien insomnia setelah cedera kepala. ${ }^{17}$

Insomnia dapat menyebabkan berbagai masalah yang secara langsung maupun tidak langsung berhubungan dengan gejala penyerta insomnia. Dalam hal gangguan psikologis, insomnia setelah cedera kepala dikaitkan dengan kecemasan dan depresi. Dalam sebuah penelitian dengan menggunakan kuisioner dikatakan bahwa kecemasan lebih sering muncul saat terjadi insomnia, yaitu $57 \%$ dibandingkan $4 \%$ dalam waktu satu tahun setelah cedera $(\mathrm{p}<0,001)$ dan $38 \%$ dibandingkan $4 \%$ pada dua tahun setelah cedera $(\mathrm{p}<0,001)$. Depresi juga meningkat menjadi 16\% dibandingkan 5\% pada satu tahun setelah cedera $(\mathrm{p}<0,001)$ dan $41 \%$ dibandingkan $13 \%$ pada dua tahun setelah cedera $(p=0,001)$. Hal yang sama juga terjadi terhadap keletihan. Penelitian yang sama menunjukkan bahwa Global Fatigue Index meningkat menjadi 31,2 dibandingkan 13,3 pada satu tahun setelah cedera $(\mathrm{p}<0,05)$ dan 31,5 dibandingkan 13,2 pada dua tahun setelah cedera $(\mathrm{p}<0,05) .{ }^{14}$ Pada penelitian lainnya dengan kuisioner yang sama didapatkan insomnia berhubungan dengan kecemasan $(\mathrm{OR}=1,44 ; \mathrm{p}=0,02)$ dan pusing atau sakit kepala $(\mathrm{OR}=0,1 ; \mathrm{p}=0,01) \cdot{ }^{15}$ Insomnia yang baru saja muncul setelah cedera kepala dapat dikaitkan dengan perburukan prognosis secara keseluruhan termasuk meningkatnya kemungkinan dari stroke $(\mathrm{HR}=2,28 ; \mathrm{p}<0,001) .{ }^{11}$ Penelitian lain juga mengatakan bahwa setiap penambahan satu poin dari Insomnia Severity Index (ISI) akan meningkatkan resiko pasien mengalami disabilitas menjadi sekitar 1,206 kali (IK 95\% 1,053-1,380). ${ }^{12}$

\section{Hipersomnia Paska Cedera Kepala}

Hipersomnia merupakan gangguan tidur yang sering ditemui pada cedera kepala. Hipersomnia memiliki prevalensi 
Tabel 1. Prevalensi, penyebab, dan dampak berbagai gangguan tidur paska cedera kepala

\begin{tabular}{|c|c|c|c|}
\hline Gangguan tidur & $\begin{array}{c}\text { Prevalensi } \\
\text { Berdasarkan Meta } \\
\text { Analisis }\end{array}$ & Penyebab & Dampak \\
\hline Insomnia & $29 \%^{13}$ & $\begin{array}{l}\text { - Diduga cedera pada daerah inferior } \\
\text { frontal, anterior temporal termasuk } \\
\text { basal otak depan }{ }^{27} \\
\text { - Peningkatan kerja saraf simpatis }{ }^{17}\end{array}$ & $\begin{array}{ll}\text { - } & \text { Kecemasan } \\
\text { - } & \text { Depresi } \\
\text { - } & \text { Peningkatan Global Fatique Index }{ }^{14} \\
\text { - } & \text { Perburukan prognosis secara keseluruhan dan } \\
& \text { peningkatan kemungkinan stroke } \\
\text { - } & \text { Peningkatan disabilitas }\end{array}$ \\
\hline Hipersomnia & $28 \%{ }^{13}$ & $\begin{array}{l}\text { - Diduga cedera pada daerah yang } \\
\text { mempertahankan bangun }{ }^{27} \\
\text { - Penurunan kadar orexin }{ }^{15,18}\end{array}$ & $\begin{array}{l}\text { - Diduga berhubungan dengan peningkatan } \\
\text { penyembuhan }{ }^{28} \\
\text { - Pertambahan waktu tidur yang menyita waktu } \\
\text { luang }{ }^{20} \\
\text { - Kecelakaan berkendara }{ }^{16}\end{array}$ \\
\hline $\begin{array}{l}\text { Gangguan ritme } \\
\text { sirkadian }\end{array}$ & Belum diketahui & $\begin{array}{l}\text { - Cedera pada nukleus suprakiasmatik } \\
\text { maupun traktusnya }{ }^{27}\end{array}$ & $\begin{array}{l}\text { - Amnesia yang lebih parah } \\
\text { - Rawat inap yang lebih lama } \\
\text { - Disabilitas yang lebih parah } \\
\text { - Penurunan kualitas tidur } \\
\text { - Penurunan fungsi sosial } \\
\text { - Penurunan kualitas hidup } \\
\text { - Peningkatan tekanan darah } \\
\text { - Penurunan detak jantung }\end{array}$ \\
\hline
\end{tabular}

beragam mulai dari $7 \%$ sampai $28 \% .^{5,6,13,15}$ Pada penelitian meta analisis dari berbagai jurnal disimpulkan bahwa prevalensi hipersomnia setelah cedera kepala mencapai angka 28\%. ${ }^{13}$

Belum ada penelitian yang memastikan hubungan hipersomnia dengan lokasi spesifik dari cedera kepala. Kejadian hipersomnia sering dihubungkan dengan tingkat GCS dan penurunan orexin (cerebrospinal fluid hypocretin). Sebuah penelitian telah menunjukkan bahwa hipersomnia berhubungan dengan GCS $(\mathrm{OR}=0,7 ; \quad \mathrm{p}<0,01)$, namun hubungan dengan penurunan kadar orexin belum terbukti secara penuh. ${ }^{15}$ Orexin dengan hypersomnia dihubungkan berdassarkan asumsi bahwa hypersomnia berhubungan dengan peningkatan GCS sama halnya dengan penurunan kadar orexin saat cedera kepala semakin berat. ${ }^{18,19}$

Hipersomnia setelah cedera kepala merupakan hal yang umum terjadi, bahkan kelainan ini bisa menetap sampai beberapa tahun. ${ }^{20}$ Berbeda dengan insomnia yang sering dikaitkan dengan perburukan kondisi dan gangguan psikologis, hipersomnia tidak secara signifikan berhubungan dengan perburukan. ${ }^{15}$ Hipersomnia sering dikatakan sebagai hal yang normal, asumsi ini bisa menjelaskan fenomena yang menunjukkan bahwa $84 \%$ sampai $100 \%$ rasa kantuk yang seperti pada umumnya akan berkurang/menghilang dalam setahun. ${ }^{21}$ Dampak negatif dari hipersomnia ini sendiri adalah perlunya penambahan waktu tidur, dimana akan menyita waktu luang dan rasa kantuk berlebih bisa mengakibatkan kecelakaan, terutama pada saat berkendara. ${ }^{16,20}$

\section{Gangguan Ritme Sirkadian Paska Cedera Kepala}

Sampai saat ini masih belum ada data yang menunjukkan prevalensi gangguan ritme sirkadian, namun sebuah penelitian menyatakan bahwa 36\% dari pasien yang mengeluhkan insomnia setelah cedera kepala ringan sebenarnya mengalami gangguan ritme sirkadian. Gangguan ritme sirkadian yang sering ditemukan adalah tipe delayed sleep-wake phase disorder dan irregular sleep-wake rhythm disorder. ${ }^{22}$

Gangguan ritme sirkadian setelah cedera kepala biasanya terjadi karena adanya cedera pada nukleus suprakiasmatik maupun traktusnya. Sebuah penelitian dengan menggunakan mencit menunjukkan adanya perubahan ekspresi gen pengatur pola tidur pada nucleus suprakiasmatik, yaitu Cryl dan Bmal1. ${ }^{23}$ Penelitian lain menunjukkan bahwa penurunan melatonin setelah cedera kepala dapat menyebabkan fragmentasi tidur dan penurunan fase
REM tanpa merubah lamanya waktu tidur dalam 24 jam. $^{24}$

Gangguan ritme sirkadian pada pasien dengan cedera kepala berat akan terlihat setelah 2 hari dan setengahnya akan menetap lebih dari seminggu. Pada pasien dengan gangguan ritme sirkadian yang menetap, diperkirakan akan mengalami amnesia yang lebih berat, lama rawat inap yang lebih lama dan disabilitas yang lebih parah. ${ }^{10}$ Gangguan ritme sirkadian secara umum juga dapat menyebabkan turunnya kualitas tidur, fungsi sosial dan kualitas hidup. ${ }^{25}$ Gangguan ritme sirkadian pada pasien cedera kepala juga diketahui dapat meningkatkan tekanan darah dan menurunkan detak jantung. ${ }^{26}$ Untuk lebih jelasnya bisa dilihat pada Tabel 1 .

\section{PEMBAHASAN}

Sebuah studi meta analisis telah dilakukan untuk memperkirakan gambaran gangguan tidur yang terjadi setelah cedera kepala, namun belum ada gambaran tentang gangguan ritme sirkadian. ${ }^{13}$ Gangguan ritme sirkadian sendiri merupakan pergeseran waktu tidur dari keadaan sebelum cedera, sehingga sangat memungkinkan gangguan ini menjadi salah diagnosis dan dianggap gangguan pola tidur-bangun lainnya seperti insomnia dan hipersomnia. Sebuah penelitian juga telah mendukung 
pernyataan ini, sebanyak $36 \%$ pasien yang mengeluhkan insomnia setelah cedera kepala ringan sebenarnya mengalami gangguan ritme sirkadian. ${ }^{22}$ Maka dari itu diperlukan penelitian lanjutan untuk mengetahui jumlah sebenarnya dari gangguan ritme sirkadian paska cedera kepala.

Masih belum ada teori yang menjawab secara tuntas mengenai penyebab terjadinya gangguan pola tidur bangun setelah cedera kepala. Salah satu teori yang paling sering dikemukakan adalah mengenai kerusakan pada daerah spesifik yang mengatur proses bangun-tidur. Insomnia setelah cedera kepala diduga karena cedera pada daerah inferior frontal dan anterior temporal serta termasuk juga gangguan pada basal otak depan sebagai salah satu pusat pengendalian siklus tidur-bangun. Hipersomnia diduga terjadi akibat cedera pada daerah yang mempertahankan fase bangun. ${ }^{27,28}$ Pada sebuah penelitian lain menunjukkan hasil yang sebaliknya. Pada tikus dengan cedera pada hipotalamus lateral yang merupakan sistem yang mempertahankan keadaan bangun, tidak selalu mengalami gangguan dalam mempertahankan keadaan bangun itu sendiri. Peneliti lain berusaha menjelaskan fenomena ini dengan asumsi ada perbedaan kemampuan kompensasi sistem-sistem yang mempertahankan fase bangun. ${ }^{29}$

Terdapat penelitian lain yang menyatakan tidak adanya hubungan antara lokasi cedera kepala dengan gangguan pola tidur-bangun. ${ }^{15}$ Hal ini bisa terjadi karena beberapa jenis kerusakan pada saraf otak tidak bisa dilihat dengan teknik radiologi konvensional, misalkan cedera DAI (diffuse axonal injury) dan kerusakan nonstruktural. ${ }^{30}$ Diperlukan sebuah studi dengan teknik neuroradiologi yang lebih sensitif dan spesifik untuk mengetahui hubungan spesifik antara jenis-jenis gangguan tidur dengan lokasi cedera kepala.

Gangguan pola tidur-bangun setelah cedera kepala dapat dikaitkan dengan tingkat perburukan maupun perbaikan. Pasien dengan gangguan ritme sirkadian yang menetap diperkirakan akan mengalami amnesia yang lebih berat, durasi rawat inap yang lebih lama dan disabilitas yang lebih parah. ${ }^{10}$ Insomnia yang baru saja muncul setelah cedera kepala dapat dikaitkan dengan perburukan prognosis secara keseluruhan. ${ }^{11}$ Hipersomnia memiliki peran ganda, yaitu dapat menunjukkan proses penyembuhan, maupun bisa bersifat patologis meskipun tidak terlalu signifikan menyebabkan gangguan. $^{15,28}$ Berdasarkan data ini, gangguan tidur bisa dimanfaatkan sebagai prediktor untuk memprediksi prognosis dari cedera kepala.

Pada hipersomnia ada sedikit pandangan unik yang justru menyatakan bahwa hipersomnia membantu penyembuhan. Penambahan waktu tidur pada fase slow wave sleep diduga menandakan terjadinya proses pertumbuhan akson, remodelling sinaps, dan perkembangan plastisitas otak jangka pendek. ${ }^{28}$ Pada percobaan dengan tikus telah dibuktikan bahwa penurunan waktu tidur dapat meningkatkan area stroke dan menurunkan fungsi motorik. Sebaliknya pemberian gamma-hydroxybutyrate yang dapat meningkatkan fase slow wave sleep akan meningkatkan perbaikan pada stroke. Mekanisme perbaikan ini juga belum sepenuhnya dipahami, namun sebuah studi menunjukkan bahwa ada peranan dari sistem glympathic yang akan aktif membuang toksin maupun produk sisa metabolisme pada saat tidur. $^{31,32}$ Namun belum ada hasil penelitian yang akurat dan kredibel mengenai hubungan proses penyembuhan pasien cedera kepala yang mengalami hipersomnia.

\section{SIMPULAN}

Pada pasien cedera kepala didapati bahwa insomnia merupakan gangguan tidurbangun yang paling sering ditemui, lalu diikuti oleh hipersomnia, namun belum ada data prevalensi dari gangguan ritme sirkadian. Mekanisme terjadinya gangguan pola tidur-bangun setelah cedera kepala belum sepenuhnya diketahui. Insomnia dan gangguan ritme sirkadian sering dihubungkan dengan lokasi tertentu dari cedera, namun hipersomnia berhubungan dengan kadar orexin dan tidak terlalu dikaitkan terhadap area tertentu. Gangguan pola tidur-bangun setelah cedera kepala memiliki banyak dampak yang dapat menjadi faktor resiko gangguan lainnya maupun sebagai tanda klinis. Insomnia dan gangguan ritme sirkadian berhubungan dengan perburukan, namun hipersomnia bisa menandakan perbaikan dan tidak berhubungan signifikan dengan gangguan lainnya.

\section{KONFLIK KEPENTINGAN}

Semua peneliti/penulis menyatakan penelitian dan penulisan naskah ini bebas dari konflik kepentingan dan dilakukan secara mandiri tanpa ada pengaruh dari pihak ketiga.

\section{SUMBER PENDANAAN}

Studi ini tidak mendapatkan pendanaan dari pihak ketiga.

\section{KONTRIBUSI PENULIS}

MKS, SM, TGBM, IWN, DPWW bersamasama menyumbang ide, merancang konsep penelitian, menyusun naskah penelitian dan bersedia bertanggung jawab atas isi naskah.

\section{DAFTAR PUSTAKA}

1. Dewan MC, Rattani A, Gupta S, Baticulon RE, Hung YC, Punchak M, et al. Estimating the global incidence of traumatic brain injury. J Neurosurg. 2018;130(4):1080-97.

2. Badan Penelitian dan Pengembangan Kesehatan. RISKESDAS 2018. 2018.

3. Ponsford JL, Parcell DL, Sinclair KL, Roper M, Rajaratnam SMW. Changes in Sleep Patterns Following Traumatic Brain Injury. Neurorehabil Neural Repair. 2013;27(7):613-21.

4. Mani A, Dastgheib SA, Chanor A, Khalili H, Ahmadzadeh L, Ahmadi J. Sleep Quality among Patients with Mild Traumatic Brain Injury: A Cross-Sectional Study. Bull Emerg trauma. 2015;3(3):93-6.

5. Gardani M, Morfiri E, Thomson A, O’Neill B, McMillan TM. Evaluation of Sleep Disorders in Patients With Severe Traumatic Brain Injury During Rehabilitation. Arch Phys Med Rehabil. 2015;96(9):1691-1697.e3.

6. Kempf J, Werth E, Kaiser PR, Bassetti CL, Baumann CR. Sleep-wake disturbances 3 years after traumatic brain injury. J Neurol Neurosurg Psychiatry. 2010;81(12):1402-5.

7. Theadom A, Cropley M, Parmar P, BarkerCollo S, Starkey N, Jones K, et al. Sleep difficulties one year following mild traumatic brain injury in a population-based study. Sleep Med. 2015;16(8):926-32.

8. Imbach LL, Büchele F, Valko PO, Li T, Maric A, Stover JF, et al. Sleep-wake disorders persist 18 months after traumatic brain injury but remain underrecognized. Neurology. 2016;86(21):1945-9.

9. Nakase-Richardson R, Sherer M, Barnett SD, Yablon SA, Evans CC, Kretzmer T, et al. Prospective evaluation of the nature, course, 
and impact of acute sleep abnormality after traumatic brain injury. Arch Phys Med Rehabil. 2013;94(5):875-82.

10. Duclos C, Dumont M, Blais H, Paquet J, Laflamme E, De Beaumont L, et al. Restactivity cycle disturbances in the acute phase of moderate to severe traumatic brain injury. Neurorehabil Neural Repair. 2014;28(5):47282.

11. Ao $\mathrm{KH}$, Ho CH, Wang CC, Wang JJ, Chio CC, Kuo JR. The increased risk of stroke in early insomnia following traumatic brain injury: a population-based cohort study. Sleep Med. 2017;37:187-92.

12. Mollayeva T, Pratt B, Mollayeva S, Shapiro CM, Cassidy JD, Colantonio A. The relationship between insomnia and disability in workers with mild traumatic brain injury/concussion: Insomnia and disability in chronic mild traumatic brain injury. Sleep Med. 2016;20:15766.

13. Mathias JL, Alvaro PK. Prevalence of sleep disturbances, disorders, and problems following traumatic brain injury: A meta-analysis. Sleep Med. 2012;13(7):898-905.

14. Cantor JB, Bushnik T, Cicerone K, Dijkers MP, Gordon W, Hammond FM, et al. Insomnia, fatigue, and sleepiness in the first 2 years after traumatic brain injury: An NIDRR TBI model system module study. J Head Trauma Rehabil. 2012;27(6).

15. Hou L, Han X, Sheng P, Tong W, Li Z, Xu D, et al. Risk Factors Associated with Sleep Disturbance following Traumatic Brain Injury: Clinical Findings and Questionnaire Based Study. PLoS One. 2013;8(10).
16. Castriotta RJ, Murthy JN. Sleep disorders in patients with traumatic brain injury: A review. Vol. 25, CNS Drugs. 2011. p. 175-85.

17. Elliott JE, Opel RA, Weymann KB, Chau AQ, Papesh MA, Callahan ML, et al. Sleep Disturbances in Traumatic Brain Injury: Associations With Sensory Sensitivity. J Clin Sleep Med. 2018;14(7):1177-86.

18. Billiard M, Podesta C. Recurrent hypersomnia following traumatic brain injury. Sleep Med. 2013;14(5):462-5.

19. Baumann CR, Stocker R, Imhof HG, Trentz O, Hersberger M, Mignot E, et al. Hypocretin-1 (orexin A) deficiency in acute traumatic brain injury. Neurology. 2005;65(1):147-9.

20. Sommerauer M, Valko PO, Werth E, Baumann CR. Excessive sleep need following traumatic brain injury: A case-control study of 36 patients. J Sleep Res. 2013;22(6):634-9.

21. Watson NF, Dikmen S, Machamer J, Doherty M, Temkin N. Hypersomnia following traumatic brain injury. J Clin Sleep Med. 2007;3(4):363-8.

22. Ayalon L, Borodkin K, Dishon L, Kanety H, Dagan Y. Circadian rhythm sleep disorders following mild traumatic brain injury. Neurology. 2007;68(14):1136-40.

23. Boone DR, Sell SL, Micci MA, Crookshanks JM, Parsley M, Uchida T, et al. Traumatic Brain Injury-Induced Dysregulation of the Circadian Clock. PLoS One. 2012;7(10):46204.

24. Shekleton JA, Parcell DL, Redman JR, PhippsNelson J, Ponsford JL, Rajaratnam SMW. Sleep disturbance and melatonin levels following traumatic brain injury. Neurology. 2010;74(21):1732-8.
25. Abbott SM, Reid KJ, Zee PC. Circadian Rhythm Sleep-Wake Disorders. Vol. 38, Psychiatric Clinics of North America. W.B. Saunders; 2015. p. 805-23.

26. Paul T, Lemmer B. Disturbance of circadian rhythms in analgosedated intensive care unit patients with and without craniocerebral injury. Chronobiol Int. 2007;24(1):45-61.

27. Viola-Saltzman M, Watson NF. Traumatic Brain Injury and Sleep Disorders. Vol. 30, Neurologic Clinics. 2012. p. 1299-312.

28. Dijk DJ. Regulation and functional correlates of slow wave sleep. J Clin Sleep Med. 2009;5(2 SUPPL.):6.

29. Lemieux M, Chen JY, Lonjers P, Bazhenov M, Timofeev I. The impact of cortical deafferentation on the neocortical slow oscillation. J Neurosci. 2014;34(16):5689-703.

30. Johnson VE, Stewart W, Smith DH. Axonal pathology in traumatic brain injury. Vol. 246, Experimental Neurology. 2013. p. 35-43.

31. Zunzunegui C, Gao B, Cam E, Hodor A, Bassetti CL. Sleep disturbance impairs stroke recovery in the rat. Sleep. 2011;34(9):1261-9.

32. Xie L, Kang $\mathrm{H}, \mathrm{Xu}$ Q, Chen MJ, Liao Y, Thiyagarajan $\mathrm{M}$, et al. Sleep drives metabolite clearance from the adult brain. Science. 2013;342(6156):373-7.

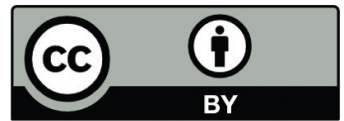

This work is licensed under a Creative Commons Attribution 